\title{
Retrospective Analysis of Pattern of Injuries in Road Traffic Accidents: An Autopsy Based Study
}

\author{
Ravi Kumar Sharma ${ }^{1}$, Himangshu Das ${ }^{2}$, Anurupa Choudhury ${ }^{3}$ \\ ${ }^{1}$ Senior Resident, ${ }^{2}$ Associate Professor, ${ }^{3}$ Assistant Professor, Department of Forensic Medicine, \\ Gauhati Medical College and Hospital, Guwahati
}

\begin{abstract}
Accidents are a counter product of modernization and hasty life and are considered as a modern day epidemic. A study was undertaken in Department of Forensic Medicine, G.M.C.H. to study of the pattern of injuries in the victims of road traffic accidents. An autopsy-based, purposive random sampling technique was applied to select the study sample of 150 post-mortem examination cases of road traffic accidents. The data collected during the study period was thoroughly analysed. Results showed that almost $90 \%(89.33 \%)$ of the victims were male. At least 44 (29.33\%) victims were of 21-30 years which was the most common age group involved. Early detection of the injury and prompt treatment are necessary in saving the lives of many of these victims. So, it is clear that multidisciplinary approach is required to prevent deaths resulting from vehicular accidents.
\end{abstract}

Keywords: Road traffic accidents, pattern, injury, fatal, prevent.

\section{Introduction}

Worldwide the number of people killed in road traffic crashes each year spastically estimated to be around 1.2 million, while the number of injured could be as high as 50 million. ${ }^{1}$ It has been predicted that by 2020, Road traffic accident will rank as high as third among causes of disability adjusted life years lost. ${ }^{2} 90 \%$ of the world's fatalities on the roads occur in low- and middle-income countries, even though these countries have approximately $54 \%$ of the world's vehicles. Road traffic accidents are the major cause of unnatural deaths among people aged between 15 and 29 years.

Estimates suggest that in India rate of death per 1000 vehicles is 1.3. According to the National Crime

\author{
Corresponding Author: \\ Dr. Himangshu Das \\ Department of Forensic Medicine, Gauhati Medical \\ College and Hospital, Guwahati \\ Phone No.: 9864033863 \\ e-mail: rahuldr77@rediffmail.com
}

Records Bureau (NCRB) ${ }^{3}$ of India, the number of accidental deaths in Assam stood at 2384 in the year 2015, While Arunachal Pradesh and Sikkim reported 177 and 75 respectively in the same year. As per bibliometric analysis, our country contributed only $0.7 \%$ research papers and articles on road traffic injuries and had less than one article on road traffic injuries per 1,000 road traffic related deaths. Accidents hence have to be studied in terms of an epidemiological model (agent, host and environmental factors) and analyzed in respect to time, place and person distribution.

\section{Material and Method}

An autopsy-based observational, cross-sectional study was conducted at the Gauhati Medical College and Hospital, Guwahati from 1st July 2017 to the 30th June, 2018. A purposive random sampling technique was applied to select the study sample of 150 post-mortem examination cases of road traffic accidents subjected to medico-legal autopsy at the department of Forensic Medicine, Gauhati Medical College \& Hospital. A pre-tested proforma was used by the investigator for interviewing the police personnels and relatives of RTA victim 
Decomposed bodies and have been exempted from the study:

Cases with no definitive history have also been excluded from the study: Data about vehicular accidents were obtained regarding age and gender of the victims, time and place of accident, type of vehicle involved in the accident, the type of injuries sustained, type of road users (pedestrians, riders, or pillions), the outcome of the accident, etc., in a self-designed pro forma (questionnaire). Data collected for each parameter were tabulated and entered into the computer using the Microsoft Excel software for further analysis.

\section{Results}

Sex and Age of Victims: The age of the victims ranged from 5 years to 78 years. The victims were divided according to their age into 7 groups. The peak incidence was observed in the age group of 21-30 years comprising of 64 cases (27.24\%) followed by 31-40 years age group with 57 cases $(24.26 \%)$. The age wise distribution of cases is shown in the figure 1 .

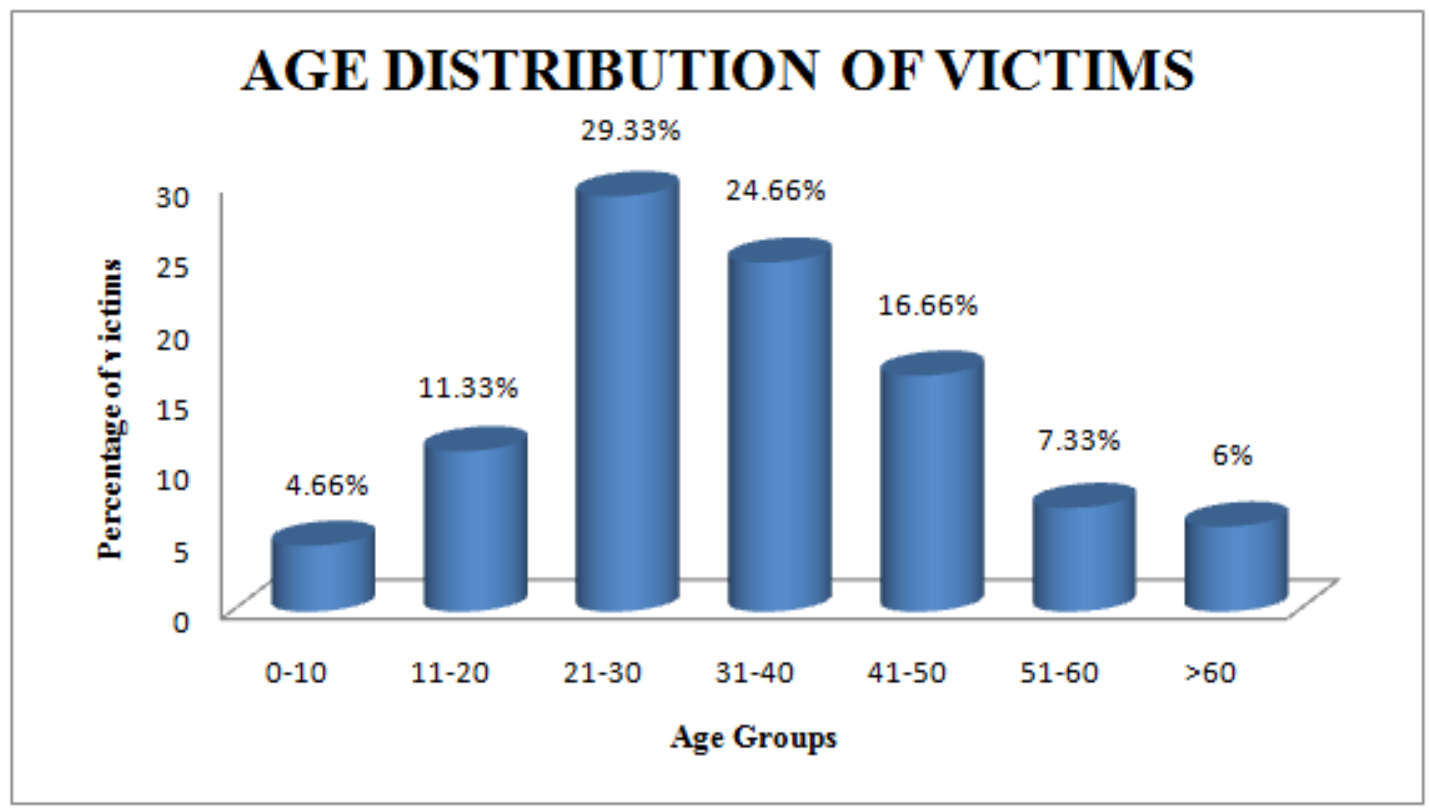

Fig. 1: Age distribution of victims

It is observed that among the 150 cases studied, 134 were male comprising $89.33 \%$ and 16 were females comprising $10.66 \%$. The male to female ratio in the present study is $8.37: 1$.

Time of Incident:

Table 1: Diurnal variation of cases

\begin{tabular}{|l|c|c|}
\hline Part of the day & No. of cases & Percentage \\
\hline 12 midnight to 6 AM & 19 & 12.66 \\
\hline 6 AM to 12 noon & 26 & 17.33 \\
\hline 12 noon to 6 PM & 51 & 34 \\
\hline 6 PM to 12 midnight & 54 & 36 \\
\hline Total & $\mathbf{1 5 0}$ & $\mathbf{1 0 0 \%}$ \\
\hline
\end{tabular}

Highest number of incidents of the present study occurred in between $6 \mathrm{PM}$ to 12 midnight (36\%) followed by almost equal number of cases in between 12 noon to 6 PM (34\%).

Period of survival: A huge number of victims died instantaneously or on the spot (31.33\%). $11.33 \%$ victims died within 1 hour and $23.33 \%$ died in between 1 hour to 6 hour.

Type of Victims and Vehicles involved: It is evident from figure 2 that a huge proportion of cases were pedestrians, 55 (36.66\%) followed by 2 -wheeler rider and occupant. 


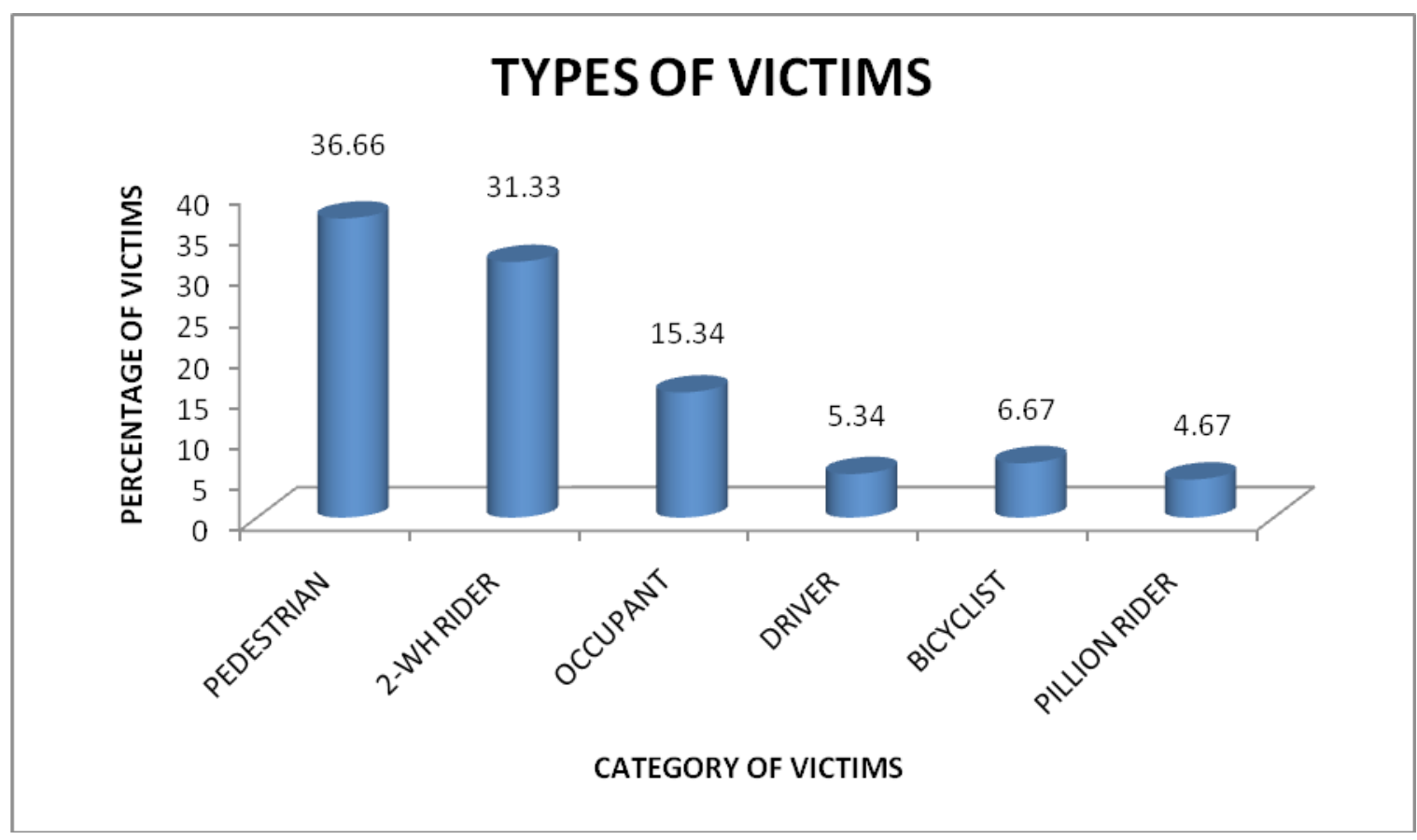

Fig 2: Different types of victims

In the present study trucks and cars are the mostly involved vehicle, $37(24.66 \%)$ in case of trucks and $33(22 \%)$ in case of cars, followed by bus and motorcycle, each in $23(15.33 \%)$ cases. In 5 cases vehicle was not known.

Pattern of injuries: The numbers of cases with injuries in different sites of the body are shown in the table no. 2.

Table 2: Site of injury of the victims

\begin{tabular}{|l|c|c|}
\hline Place of injury & No. of cases & Percentage \\
\hline Chest+Head & 8 & 5.33 \\
\hline Chest+Abdomen & 0 & 0 \\
\hline Chest+Limbs & 4 & 2.66 \\
\hline Chest+Head+Abdomen & 2 & 1.33 \\
\hline Chest+Head+Limbs & 52 & 34.66 \\
\hline Chest+Abdomen+Limbs & 19 & 12.66 \\
\hline All regions & 65 & 43.33 \\
\hline Total & 150 & 100 \\
\hline
\end{tabular}

In the present study most of the victims (65 or $43.33 \%$ ) had injury on all regions of the body, followed by Chest + Head+Limbs (52 or $34.66 \%$ ). None of the victims had injury only on chest. Along with other regions limbs are involved in most of the cases (140 or $93.33 \%)$.

Abrasion on the body was found in total 103 cases. Out of these, associated contusion was present in 80 cases and associated laceration was found in 33 cases. In 3 cases no external injuries were found as depicted in figure no. 3 .

Lungs were injured in 77 cases (51.34\%) among the total 150 cases. It was observed that heart was injured in a total number of 8 cases (5.34\%). Liver was involved in 55 cases $(74.32 \%)$ of total cases with intra abdominopelvic injuries. Lacerations were present on 48 cases (64.86\%), Contusion on 3 cases $(4.05 \%)$ and crush injuries over 4 cases $(5.4 \%)$. 


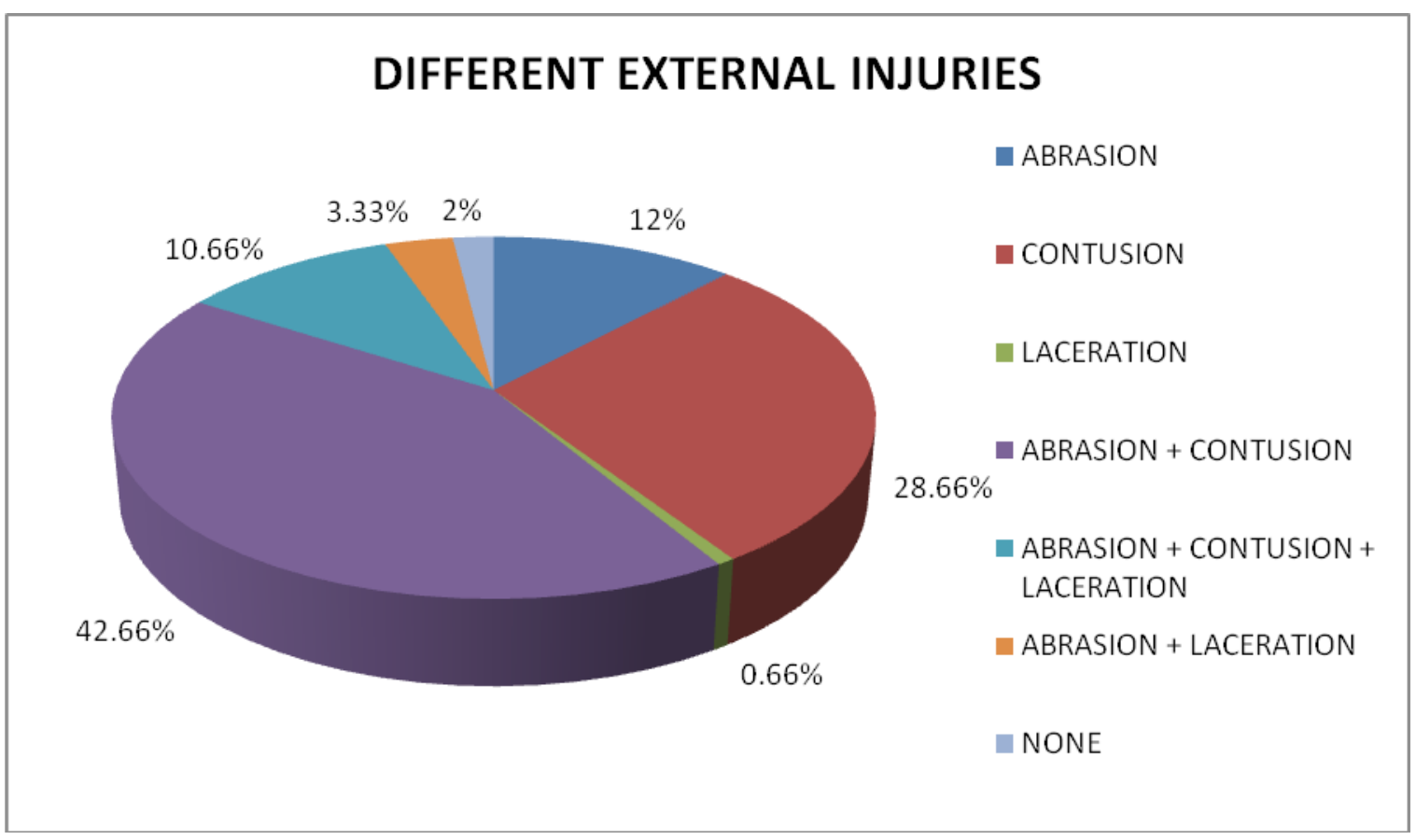

Fig 3: Pi-diagram of percentage of incidence of various external injuries

Spleen was involved in 29 cases: In 14 cases injuries were detected over kidney. Out of 14 cases, in 3 cases it was present over right kidney and in 7 cases injuries were present over left kidney while in 4 cases it was bilaterally present.
Cause of death: Coma without haemorrhage and shock is the most common cause of death (41.24\%) followed by haemorrhage and shock without coma (32.67\%). Death was instantaneous in $13.95 \%$ cases.

Table 3: Causes of death among the victims

\begin{tabular}{|l|c|c|}
\hline Cause of death & No. of victims due to vehicular accidents & Percentage \\
\hline Coma & 476 & $41.24 \%$ \\
\hline Haemorrhage and shock & 377 & $32.67 \%$ \\
\hline Coma + haemorrhage and shock & 107 & $9.27 \%$ \\
\hline Instantaneous & 161 & $13.95 \%$ \\
\hline Exhaustion & 7 & $0.61 \%$ \\
\hline Spinal shock & 19 & $1.64 \%$ \\
\hline Syncope & 7 & $0.61 \%$ \\
\hline Total & $\mathbf{1 1 5 4}$ & $\mathbf{1 0 0 . 0 0 \%}$ \\
\hline
\end{tabular}

\section{Discussion}

In the present study, peak incidence was observed in the age group of 21-30 years comprising of 44 (29.33\%) cases. This is closely followed by age group 31-40 years with $37(24.66 \%)$ cases and $41-50$ years with 25 $(16.66 \%)$ cases. This means that $106(70.67 \%$ of total $)$ people lost their in prime of their life. Age groups 0-10 years ( 7 cases), 51-60 years ( 11 cases) and $>61$ years ( 9 cases) have less number of cases. These findings are consistent with Goyal A. et al.(2014) ${ }^{4}$, Reddy N. B. $(2014)^{5}$, Shrivastava S. R. $(2014)^{6}$, Seid M. et al. $(2015)^{7}$, Sharma S. M. $(2016)^{8}$, Singh S.K. (2017) ${ }^{9}$, Smith et al. $(2017)^{10}$. 
In the present study males comprises a majority $(89.33 \%)$ compared to female who were only $11 \%$. Male to female ratio is $8.37: 1$ which is congurent with Goyal A. et al.(2014) ${ }^{4}$, Reddy N. B. $(2014)^{5}$, Shrivastava S. R. $(2014)^{6}$, Seid M. et al. $(2015)^{7}$, Sharma S. M. $(2016)^{8}$ and Singh S.K. (2017) $)^{9}$.

. The reason for the male majority is the patriarchal setup of our society where men are exposed to outdoor activities to earn bread and other work, travelling between the home and place of work, while women mostly remain indoors at the home involved in household work.

Highest number of cases died in accidents that took place in between $6 \mathrm{PM}$ to 12 midnight (36\%) followed by almost equal number of cases in between 12 noon to 6 PM (34\%). So total of 70\% accidents are found to occur between 12 noon to 12 midnight.

These findings are consistent with NCRB (2015) ${ }^{3}$. This can be due to the people returning from place of work and activity at that time leading to traffic rush, fatigue of the people nearing the end of day, improper driving condition in the dark and people visiting commercial places more at that time of the day.

In this study a huge proportion of cases were pedestrians $(36.67 \%)$ followed by two wheeler rider (32.67\%).These findings are consistent with Sharma S.M. $(2016)^{8}$.

High incidence of pedestrians (36.67\%) among the victims (most common age group 30-41 years) may primarily be due to increasing number of people on the road, ignorance of the people about traffic rules and discipline, lack of proper walking lanes in the streets. Next are the riders of 2-wheeler majority of which comprises of students and young professionals (most common age group 21-30 years) whose enthusiasm for speed and adventure make them prone to such accidents. Poorly maintained roads and lack of balance of the vehicle itself are important factors.

In the present study trucks and cars are the mostly involved vehicle, 37 cases (24.67\%) and 33 cases (22\%) respectively, followed by bus and motorcycle, each in 23 cases (15.34\%). Among these four wheelers are most common. These findings are consistent with, Goyal A. et al. $(2014)^{4}$ and Sharma S.M. $(2017)^{8}$.

Guwahati city is a huge business and education centre of North East India. So, lots of people travel to and from the city for all sorts of purposes like business and educational purposes. City has increasingly high number of 4 and 2 wheelers with same narrow lane roads. Parking facilities are inadequate, so vehicles are parked on already stressed roads. National highway passes through the outskirts of the city with lots of heavy vehicles. Construction activities are on rise due to economic growth.

In this study majority of victims died within 1 hour of accident including those who died instantaneously (total $42.66 \%$ ). 35 victims (23.34\%) died within 1hour to 6 hour. Total 115 victims $(76.67 \%)$ died within 24 hours following accident which is the most crucial period in management.

These findings are consistent with Reddy N.B. $(2014)^{5}$.

These findings highlight the importance of the Golden Hour in the management of trauma and emergency. The first hour after any accident is the most crucial and survival increases if care and treatment is provided to victims on the spot and on the way to hospitals.

In this study, incidence of thoraco-abdominal injury among all cases of vehicular accident is $48.7 \%$. In all the cases (150 cases) chest injury is associated with one or more other region injury. In majority of cases (43.33\%) all regions of the body are involved. Head injury is associated with total $84.65 \%$ cases.

External injuries were found in 150 cases of the study. Among all the cases $4(2.67 \%)$ victims have internal injury without external injury and 35 (23.34\%) victims have external injury without internal injury. Abrasion is present in 18 victims and contusion is present in 43 victims. From the above observation it can be said that from external examination of a victim it is difficult to judge the extent of internal injury in a significant number of cases.

Laceration of lung is more common than contusion and bilateral involvement is more common than unilateral injury. Right side involvement is more common than left side. In three case lungs are crushed. Again lung involvement is most common in pedestrians.

Heart was injured in a total number of 8 cases $(5.34 \%)$, on the basis of naked eye examination and histopathological examination. Laceration is more 
common than contusion. In one case heart is found to sustained crush injury. Among the different types of victims, heart is most commonly involved in pillion rider $(16.67 \%)$. These finding are almost consistent with Reddy et al. (2014) $)^{5}$ and El-Menyar (2016) ${ }^{11}$.

In the present series, liver injuries were observed in 55 cases comprising the highest number of cases. Majority of the cases had involvement of right lobe of the liver and anterior surface of the liver. Similar findings have been described by Gushinge and Kadu (2017) ${ }^{12}$. In the present study pedestrians have been found to be involved in 14 cases.

There were 29 cases of spleen injuries in almost all circumstances the spleen was lacerated (26 cases). Spleen is the next solid organ after liver to be injured most. Spleen injuries associated with rib fractures have also been reported by Reddy et al (2014) .

In the present study, kidney was involved in 14 cases (18.91\%). Of these 14 cases, 2 cases were lacerated, 9 cases were contused and 1 was crushed. High incidence of kidney injuries was involved in the study of Gushinge and Kadu (2017) ${ }^{12}$. In the present series majority was lacerated due to blunt force impact resulting from vehicular accidents.

In this study coma without haemorrhage and shock is the most common cause of death (41.24\%) followed by haemorrhage and shock without coma (32.67\%). Death was instantaneous in $13.95 \%$ cases.

\section{Conclusion and Recommendations}

Vehicular accidents continue to be a growing menace, incurring heavy loss of valuable man-power and human resources, along with a corresponding drain of potential economic growth. Primarily three factors comprise road safety - infrastructure (roadways), vehicle design and human behaviour. So, we suggest following strategies to prevent road traffic incidents -

Enforcement of traffic laws especially to control speed, use of safety belts and road worthy vehicles should be enhanced.

Safe crossings and sidewalks or separate paths and lanes for pedestrian and cyclists should be built.

First aid at the scene of crash and appropriate medical care in emergency rooms is a must to save life of the victim.
Hospitals with trauma units should be built along major highways for quick access for post crash victims.

In modern days of busy life with stress and strains many people are fraught with worries and anxieties. This has a deleterious effect on the power of mental concentration which is very much essential in driving. Another important factor in incidents of road traffic accidents is that people talk on their mobile phone while driving which reduces concentration on vehicle by the driver. So banning of mobile phone while driving which is to be strictly implemented. Another detrimental factor in incidents of vehicular accidents is the influence of alcohol and drugs on the drivers. The use of alcohol measuring gadgets may solve this factor. Value of seat belt and crash helmets is very much important in preventing fatal injuries.

So, it is clear that multidisciplinary approach is required to prevent deaths resulting from vehicular accidents.

\section{Funding: None}

Conflict of Interest: There are no conflicts of interest

\section{Ethical Clearance: Obtained}

\section{References}

1. Women and health: today's evidence tomorrow's agenda [Internet]. World Health Organization. 2018 [cited June 4 2018]. Available from: https://www.who.int/gender-equity-rights/ knowledge/9789241563857/en/

2. Ghaffar A, Hyder AA, Masud TI. The burden of road traffic injuries in developing countries: The first national survey of Pakistan. Public Health 2004;118:211-7.

3. Accidental deaths and suicides in India [Internet]. Ncrb.gov.in. 2018 [cited June 4 2018]. Available from: http://www.ncrb.gov.in/StatPublications/ ADSI/PrevPublications.htm

4. Goyal A, Oberoi SS, Agarwal KK, Aggarwal AD. Pattern of Injuries Cases in the mortuary in the year 2011-2014 in Rajindra Hospital Patiala. J Punjab Acad Forensic Med Toxicol. 2014;14(2):105-7.

5. Reddy NB, Hanumantha null, Madithati P, Reddy NN, Reddy CS. An epidemiological study on pattern of thoraco-abdominal injuries sustained in fatal road traffic accidents of Bangalore: Autopsy- 
based study. J Emerg Trauma Shock. 2014 Apr;7(2):116-20.

6. Shrivastava SR, Pandian P, Shrivastava PS. J Neurosci Rural Pract. 2014 Nov;5(Suppl 1):S33-8. doi: 10.4103/0976-3147.145198.

7. Seid M, Azazh A, Enquselassie F, Yisma E. BMC Emerg Med. 2015 May 20;15:10. doi: 10.1186/ s12873-015-0035-4.

8. Sharma SM. Road Traffic Accidents in India. Int $\mathbf{J}$ Adv Med Sci. 2016;1(2):57-64

9. Singh SK. Road Traffic Accidents in India: Issues and Challenges. Transportation Research Procedia. 2017;25:4708-19.
10. Smith A, Smith H. Perceptions of risk factors for road traffic accidents. Advances in Social Sciences Research Journal [Internet]. 2017 Jan 25 [cited 2018 Jun 21];4(1). Available from: http://www. scholarpublishing.org/index.php/ASSRJ/article/ view/2616

11. El-Menyar A, Abdelrahman H, Al-Hassani A, Ellabib M, Asim M, Zarour A, et al. Clinical Presentation and Time-Based Mortality in Patients With Chest Injuries Associated With Road Traffic Accidents. Arch Trauma Res. 2016 Mar; 5(1):e31888.

12. Gushinge M, Kadu S. International Journal of Education and Research in Health Sciences, AprilJune 2017;3(2):90-92 